\title{
Research and Discussion on Practical Teaching Reform of Control Surveying
}

\author{
Yan Wang, Jinbo Qu, Yingchun You \\ School of Transportation Engineering \\ Shenyang Jianzhu University \\ Shenyang, China \\ wyan413@163.com
}

\begin{abstract}
In order to meet the needs of the applicationoriented transformation of surveying and mapping, a series of reforms were made to the experiment and practice of "control survey" from three aspects: teaching content, teaching methods and assessment methods. In terms of teaching content, triangulation and other outdated content have been removed, and new methods such as free station have been added. In terms of teaching methods, heuristic teaching methods have been used to encourage students to find information and make plans. In terms of assessment methods, the students' personal skills and practice level have been mainly assessed, and the results of team work were only one of the reference points for performance evaluation. After the reform, the practice experiment content is more close to the production practice. Fully mobilize the enthusiasm and initiative of the students, the assessment is more just and reasonable. Practice has proved that the teaching reform has achieved good results.
\end{abstract}

Keywords-Control surveying; Practical teaching; Reform; Application-oriented transformation

\section{INTRODUCTION}

The development of surveying and mapping technology is changing rapidly. New instruments, new technologies, new methods are constantly emerging, which control huge changes in measurement technology. The new requirements for the control of practice teaching of surveying, must match the production practice of practice teaching. In November 2015, the ministry of education and other ministries jointly issued "the guidance on the guiding part of local colleges and universities to change the application type". It guides and promotes the transformation of some colleges and universities, professional to application. Surveying and Mapping Engineering in many colleges and universities have been included in the application of transformation pilot professional. Under this background, practical teaching of Control Surveying need to reform the traditional teaching mode, contents , teaching plan and examination methods [1-2].

\section{CURRENT SITUATION OF PRACTICAL TEACHING OF CONTROL SURVEYING}

Firstly, practical teaching of Control Surveying has been continued the more mature experiment, exercitation program. The experiments are mainly focuses on precise angle measurement, precise ranging and precise leveling, and the exercitations are focuses on triangulation and traverse surveying. However, in the application of the transformation of the background, less due to the application of new technologies and new methods, traditional practice has been unable to meet the current needs [3].

Secondly, for the teaching plans of practical teaching, the school also has some time to arrange teaching hours is too small, not fixed, and the other pilot courses or follow-up courses do not match the phenomenon, caused a certain impact on the effectiveness of teaching practice. Currently some schools still have the phenomena that the hours are too small, the time arrangement is not fixed and it does not match other teaching arrangements for pilot courses and subsequent courses which have a certain impact on the effect of practical teaching[4].

Finally, in the aspect of practice examination, most of the assessment is based on group assessment, and the results are combined with quality and personal performance, personal assessment items are few, and the scoring is mainly qualitative scoring, and the proportion of quantitative scoring is smaller, even that there is no quantitative scoring system, which leads to poor objectivity in practice assessment [5]

\section{PRACTICAL TEACHING REFORM PROGRAM}

In view of the current situation of practice teaching of Control Surveying, in order to meet the needs of the application type transformation, we should make large scale of practice teaching for the reform and practice from the experiment and practice of teaching content, teaching methods, assessment criteria and methods [6].

\section{A. Reform of the content of practice teaching}

In order to adapt to the needs of professional surveying and mapping application pilot transformation, the setting of theoretical curriculum and teaching methods need to be adjusted. In practice teaching, it is necessary to make a reasonable adjustment of teaching content, to reduce the content of outdated, practical value, and increase the new technology and new methods in production practice [7].

According to the above requirements, with Shenyang Jianzhu University surveying and mapping engineering as an 
example, the practice teaching content of Control Surveying has carried out a large-scale adjustment. The main adjustment is as shown in table 1.

TABLE I. ADJUSTMENT PLAN OF PRACTICAL TEACHING CONTENTS OF CONTROL SURVEYING

\begin{tabular}{|c|c|c|c|c|}
\hline Project & Nature & Original class hour & Hours after the reform & Reform mode \\
\hline $\begin{array}{l}\text { Understanding and use of } \\
\text { precision optical theodolite }\end{array}$ & Experiment & 4 & 2 & Cut hours \\
\hline $\begin{array}{c}\text { Horizontal angle observation \& } \\
\text { precise angle measurement }\end{array}$ & Experiment & 4 & - & Delete experimental content \\
\hline $\begin{array}{l}\text { Precise angle measurement with } \\
\text { total station }\end{array}$ & Experiment & - & 4 & New experiment \\
\hline $\begin{array}{c}\text { Precise distance measurement with } \\
\text { total station }\end{array}$ & Experiment & 4 & 2 & Cut hours \\
\hline $\begin{array}{l}\text { Understanding and application of } \\
\text { precision optical level }\end{array}$ & Experiment & 4 & 2 & Cut hours \\
\hline $\begin{array}{c}\text { Understanding and use of } \\
\text { electronic level }\end{array}$ & Experiment & - & 2 & New experiment \\
\hline Precise height control survey & Experiment & 4 & 8 & Increase content of experiment \\
\hline $\begin{array}{l}\text { Design and calculation of geodetic } \\
\text { control network }\end{array}$ & Experiment & 4 & - & Delete experimental content \\
\hline $\begin{array}{l}\text { Triangulation diagram design and } \\
\text { reconnaissance point }\end{array}$ & Experiment & - & 4 & Practice transfer experiment \\
\hline $\begin{array}{l}\text { Layout and implementation of } \\
\text { triangulation network }\end{array}$ & Exercitation & 2 weeks & - & Delete exercitation content \\
\hline $\begin{array}{l}\text { Layout and implementation of } \\
\text { fourth-class leveling network }\end{array}$ & Exercitation & 1 week & - & Delete exercitation content \\
\hline $\begin{array}{l}\text { Layout and implementation of } \\
\text { precise traverse }\end{array}$ & Exercitation & - & 1 week & New exercitation content \\
\hline $\begin{array}{l}\text { Layout and implementation of } \\
\text { second-class leveling network }\end{array}$ & Exercitation & - & 1 week & Improve practice requirements \\
\hline $\begin{array}{l}\text { Layout and implementation of } \\
\text { GNSS plane control network }\end{array}$ & Exercitation & - & 1 week & New exercitation content \\
\hline $\begin{array}{l}\text { Free station method of plane } \\
\text { control network }\end{array}$ & Exercitation & - & 1 week & New exercitation content \\
\hline
\end{tabular}

In Table 1, the experimental contents are mainly reformed from the following aspects.

\section{1) Reducing the experimental links of traditional instruments \\ In the aspect of angle measurement, there are 8 class hours of experiments on the use of $\mathrm{J} 2$ theodolite. But at present, the production unit has no longer use $\mathrm{J} 2$ optical theodolites. Therefore, only 2 class hours of experiments have been preserved after reform, which is "Understanding and use of precision optical theodolite", and the experiment "Precise angle measurement with total station" has been added. In the aspect of leveling, the experimental project of optical level is reduced and the experimental project of electronic level is added.}

\section{2) Reducing practice hours for triangulation}

With the gradual maturity of GNSS technology and the advent of high precision total stations, the accuracy of GNSS control network and precision traverse network has improved. They can replace most of the triangulation. Therefore, the triangulation content is removed from the exercitation, and the experiment of triangulation is only retained 4 class hours.

\footnotetext{
3) Increasing the practical hours for precise traverse measurements and GNSS measurements
}

After the triangle net has exited most engineering projects, the precise traverse network and the GNSS network have gradually occupied the leading position of the plane control survey. In the exercitation, first class traverse control net and $\mathrm{E}$ class GNSS control net have been added, which are fully matched with the production practice in two aspects.

4) Increasing practice content of free station method of control network

With the continuous increase of long tunnel, specialty tunnel and urban subway construction, the method of free station for control network of tunnel construction is more and more popular by the engineering builders. Although the free station method has been gradually popularized in recent years, it is seldom involved in the teaching and practice of colleges and universities.

In order to meet the needs of precision engineering, the contents of free station method have been increased, which require layout control net by free station method.

5) Increasing content of underground height transfer in exercitation

At the height of tunnel construction control survey work, in addition to the surface of the precise leveling network, also need to pass to inside the tunnel elevation. Therefore, in the 
exercitation, the contents of elevation transfer have been added. The elevation transfer of large height difference has been required.

\section{B. Reform of practical teaching methods}

Practical teaching not only needs to change the content of practical teaching, but also needs to carry out a series of reform from the teaching methods, which can inspire students to think about problems, design projects, and complete the task of practice. The teaching methods of control surveying in practice are mainly reformed from the following two aspects.

\section{1) Adopting heuristic teaching method}

After the reform of the practice of control surveying, teachers are required to adopt heuristic teaching mode [8]. Teacher no longer lays down detailed experimental or exercitation guide book, and only do experimental or exercitation assignments. Students themselves need to find information to make plans, and teachers should judge both the process of practice and the results of practice.

For example, in the exercitation of control surveying, one of the tasks is layout a first class traverse control net. Teachers regulate the range and traverse point number, and provide students with several alternative instruments. Students find information and measurement standards, and make plans from the selection of equipment, the traverse point survey location, mark stone embedment, measurement, the determination of the number of limit error identification, error point evaluation and other aspects. It enables students to master the whole process of precise traverse layout, and greatly improves the effect of exercitation [9].

\section{2) Everything is based on measurement standards}

In order to adapt the application of transformation needs, all-round contact with real mapping work, after the teaching reform, teachers no longer alone give students the provisions of technical indicators. All indicators shall be subject to the relevant measurement standards, which let students develop a habit of checking standards, and regulating everything, and help students familiar with the criterion, for the industry to lay a good foundation.

\section{Reform of practice assessment}

In addition to adjusting the teaching content and improving the teaching mode, the assessment methods also directly affect the enthusiasm and initiative of the students [10]. Therefore, the assessment model of experimental and exercitation measurement of Control Surveying has been reformed.

\section{1) Reform of examination method of experiment}

The experiment of control surveying has no separate results, only as part of the overall score of the control surveying theory course. Before the reform, the experimental results accounted for $10 \%$ of the total score of the course, and the experimental results were generally evaluated only by the results of the experiment report. The impartiality and proportion were low, which could not arouse the attention of the students.

After the reform, the proportion of experimental results increase to $20 \%$ firstly, and then more attention should be paid to the process assessment. The experiment report only serves as a reference for the grading, and the emphasis lies on the standardization of the experiment process and the accuracy evaluation of the results, so as to fully arouse the enthusiasm of the students.

\section{2) Reform of examination mode in exercitation}

The exercitation of control surveying has 4 credits, which is one of the most professional exercitation. Before the reform, the evaluation of the exercitation results was mainly based on the quality of team outcomes, and fewer personal assessment items, resulting in a slight lack of fairness.

After the reform, the assessment is more prominent personal ability. It adds a personal instrument operation, individual design two-part examination content. The assessment of the total score is carried out according to the following formula.

$$
S=S_{1} \times 50 \%+S_{2} \times 30 \%+S_{3} \times 20 \%
$$

In the model, $\mathrm{S}$ is the total score of practice, $S_{1}$ is the score for personal instrument operation, $S_{2}$ is the score for individual project design, $S_{3}$ is the score for team achievement evaluation. All scores are 100 percent system.

The operational part of the individual instrument is mainly evaluated by the operation of the total station and precision level, and station operation and data processing of direction observation method and second class leveling. The design of the individual scheme is mainly based on the content of the internship and the given project background, which requires the design of the complete measurement scheme within the specified time. The result of the team is judged by the results of the individual's training group.

After the examination method reform, each student must pass the rigorous instrument operation examination and the plan design examination. Reform encourages students to practice carefully during their exercitation, which has achieved "to test, to promote practices" the goal.

\section{CONCLUSION}

After the reform of the three aspects of practical teaching content, practice teaching methods and practice assessment methods, the contents of control surveying practice teaching are more close to production practice. Students' ability to think and solve problems is greatly improved. The assessment method is more fairer. The overall teaching effect has been greatly improved, and the employing unit also gives a higher evaluation. Reform has reached the purpose of surveying and mapping application professional transformation, and achieved good results.

\section{ACKNOWLEDGMENT}

This work was supported by 2017 China Construction Education Association education teaching and research projects (Project Nos. 2017077).

Yan Wang received the B.E. and M.E. degrees in geodesy and surveying engineering from Hohai University, Nanjing, China in 2002 and 2005. He is currently an associate professor 
in School of Traffic Engineering, Shenyang Jianzhu University. His main research direction is the precise survey engineering.

E-mail: wyan413@163.com

\section{REFERENCES}

[1] Jinxia Jiang. The Innovation Practice Case in Control Survey Teaching: Take the Second Order Leveling Teaching for Example [J]. Geomatics \& Spatial Information Technology, 2016,39(7):45-46.(In Chinese)

[2] Daqi Shi, Liang Leng. Practice and Effect of Teaching Reform on "Control Surveying"[J]. Geomatics \& Spatial Information Technology, 2015, 38(5):196-201. (In Chinese)

[3] Mingjian Chen, Hui Ju. Reflection on the Didactical Practice on the Course of " Control Surveying" in High Vocational Education [J] Mine Surveying, 2015,(3):94-96. (In Chinese)

[4] Weicheng Zhao, Fuyi Ma, Xin Ye. Study on the Construction of the Course "Control Surveying" under Application -oriented Talents Training Mode [J]. Mine Surveying, 2014,(4):98-100. (In Chinese)
[5] Liu Yang. Exploration and Practice of Questioning Teaching Method of Control Surveying [J]. Journal of Geomatics, 2011,36(3):52-54. (In Chinese)

[6] Yuelei Qian. Research of Education Reform for Control Surveying under Registered Surveyor System [J]. Beijing Surveying and Mapping, 2013,(4):99-101. (In Chinese)

[7] Zhenhong Xie, Bo Fu, Zhongli Wang, Xiaoguang Wang, Huaibao Wang Theory and Practice Optimization of Control Surveying [J].Journal of Jilin Institute of Architecture \& Civil Engineering, 2011, 28(6):11-14. (In Chinese)

[8] Yan Wang, Maohua Liu, Yingchun You. Research on the Training Mode of Surveying and Mapping Major Students under the Applicationoriented Transformation Pilot [J]. Bulletin of Surveying and Mapping,2016,(11): 144-147. (In Chinese)

[9] Hongbao Dai, Jiying Xu. Teaching Reform and Pondering of Control Surveying in Applied Undergraduate [J]. Yinshan Academic Journal(Natural Science Edition), 2015,29(4):85-88. (In Chinese)

[10] Yan Wang, Maohua Liu, Lijun Yang. Research and Practice on the Method of Synchronous Teaching with 'Control Surveying' and 'GNSS Principle'. [J]. Bulletin of Surveying and Mapping, 2016,(10): 141-143. (In Chinese). 